\title{
Industrial textile application using advanced technology
}

\author{
Thouraya Hamdi, Jmali Mohamed \\ ${ }^{I}$ (National Engineering School, Thermal and Energetic Systems Studies Laboratory ,University of Monastir, \\ Ibn Aljazzar Street, Monastir 5019, Tunisia \\ ${ }^{2}$ (Textile Engineering Laboratory, University of Monastir, ISET Ksar Hellal, Monastir-Ksar Hellal,Tunisia
}

\begin{abstract}
During the past decade, and in view of competition concerns, tunisian industrial companies have placed considerable emphasis on their information systems. Also, new technologies of information and communication technologies (ICT) have played a key role in improving the organization and traditional information systems. To be effective, it is essential to have a clear vision of the field to computerize and trends. Among the key concepts recently developed, designated by the term ERP (Enterprise Resource Planning) is the priority of business. This is a significant advancement over conventional techniques and approaches. More than a breakup is an extension of previously performed procedures. In this study, we set an industrial textile application using the Visual basic and a good result was found.
\end{abstract}

Keywords: - Production, Management, Visual Basic, Dyeing.

\section{INTRODUCTION}

Getting Management the production of a business is to find a feasible solution with respect to objectives while adjusting a set of resource conflicts. The course computer aided production management aims to raise awareness on the one hand the production systems, functions and management approaches that can be associated other hand IT tools that can be implement for decision support[1]. In most industrial companies, production costs (raw materials, hands direct and indirect work) represent on average $75 \%$ of turnover. The profitability of the company depends on its production management, which has three ways but conflicting objectives: Reducing delivery. Return on the production tool. Secure the minimum stock. Very few companies have mastered these objectives because they do not yet have a management computer aided production. In his book, Blondel sweeps the field of production management, with a particular focus on the ERP (computer aided production management). He share system of company organization, then moved to the production system and related functions, and finally address the technical[2]. Then we noted that Schoefs deals each topic a conceptual overview, followed by an explanation of the process to refine the implemented methodology[3]. Blondel presents the principles, qualitative and quantitative methods to increase the level of organization, productivity and knowledge capitalization[4], It is organized into three parts: What? to define precisely the objects (articles, BOMs, routings, etc..) used in the business. How? manager brings to all the definitions and methods of industrial management functions (stocks, just-in-time, ECR, maintenance, etc.). How much? the means of controlling and describes the decision support techniques as well as their context of use. Maurice et al explain and illustrate the different tools and methods for production management, from traditional to innovative, explained, illustrated and compared. They include the basic methods of production management and computerization of these (chapters 2-10), the second on methods of improving production (Chapters 11-15) by giving emphasis on the philosophy of Lean Manufacturing: the company in motion with Lean, the main tools of Lean, the implementation of the workshops, performance indicators[5].

The industrial company must now face new strategic challenges and constantly adapt its organization to its market, its customers and new distribution channels such as the Internet. For some time (early 1990s ), the industrial world is ignited by a new IT management solution, namely the integrated management software packages often designated by the term ERP acronym for " Enterprise Resource Planning ". However, since about 1995 , Tunisian firms have devoted considerable attention to these ERP various facilities took place. Others are in progress. From this observation, we present the software tools used to build an application for production management. These tools offer a good data handling and extensive flexibility. These tools are Visual Basic and Microsoft Access program.

\section{VISUAL BASIC}

\section{THE COMPUTER APPLICATIONS USED}

Visual Basic is a language of visual and event programming. It allows you to build applications in three phases:

- Design of the GUI. This is to build windows and other graphics objects using drawing tools.

- Assigning values to certain properties of the graphical objects. 
- Write code to associate actions with graphical objects.

Visual Basic has several working windows to create an application. The creation of a visual form is interactively. The user selects the controls in the toolbox (3) and deposited on the sheet (4). He customizes changing property values using the Properties window (2). As for writing programs, it is in the code window of a sheet file:

$>$ The object window contains a list of all objects (sheet and controls) of the application

$>$ The code window of a module has the same appearance as that of a sheet, except that it has the general object.

Finally, the project window (1) manages all paper files and / or modules that make up the application.

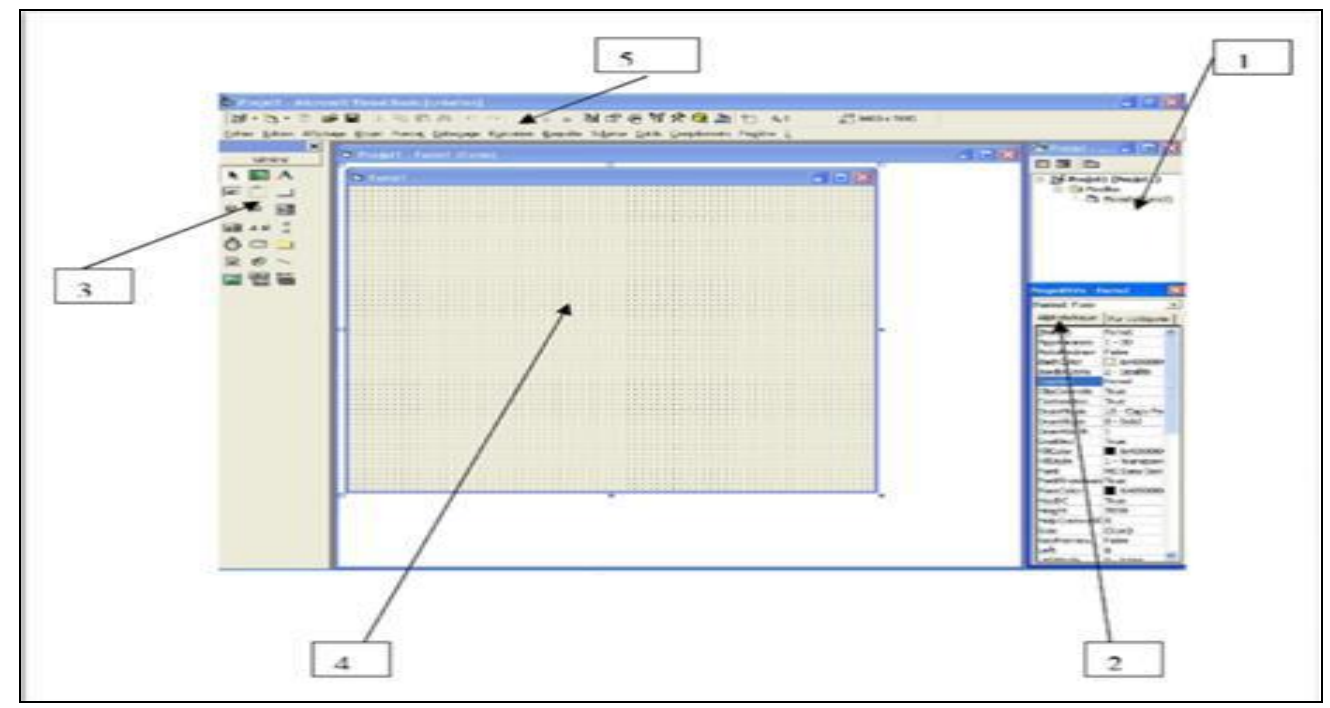

Figure.1: Visual Basic window

\section{MICROSOFT ACCESS}

Access is a software for easy design databases "small" size with a small number of users. Access is based on the relational model and works on the principle that system information is stored in tables that are linked by relationships. Querying the database is done using queries. In addition, it incorporates a system of clear and simple applications created for each database.

\section{RESULTS AND DISCUSSION}

This tool contains several helper applications for service production and workflow management. These applications provide the ability to manage the production cycle starting from the reception, to delivery and launch to billing. Each interface of this application makes a record set related to the corresponding base and data filtering capabilities and print various forms necessary and good in production.

Table 1: The Main Control Buttons.

\begin{tabular}{|c|c|c|}
\hline Command Button & Name & Function \\
\hline Dos & Write & Write in the textarea \\
\hline [L] & Register & Saves the data entered in the corresponding database \\
\hline 军 & Print & Prints the selected data or all data on the corresponding database \\
\hline (a) & Remove & Deletes the selected data \\
\hline 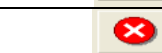 & Leave & Exits the active interface \\
\hline
\end{tabular}

\section{Customer}

Upon activation of the interface displays a table indicating all recorded data of customers, data entry help to know all the information necessary for the continuation of operations. By selecting the desired client (corresponding line) is used to view the data in the corresponding text boxes. We can intervene at this level to change any of the data and save it back to the corresponding base (Figure 2). 


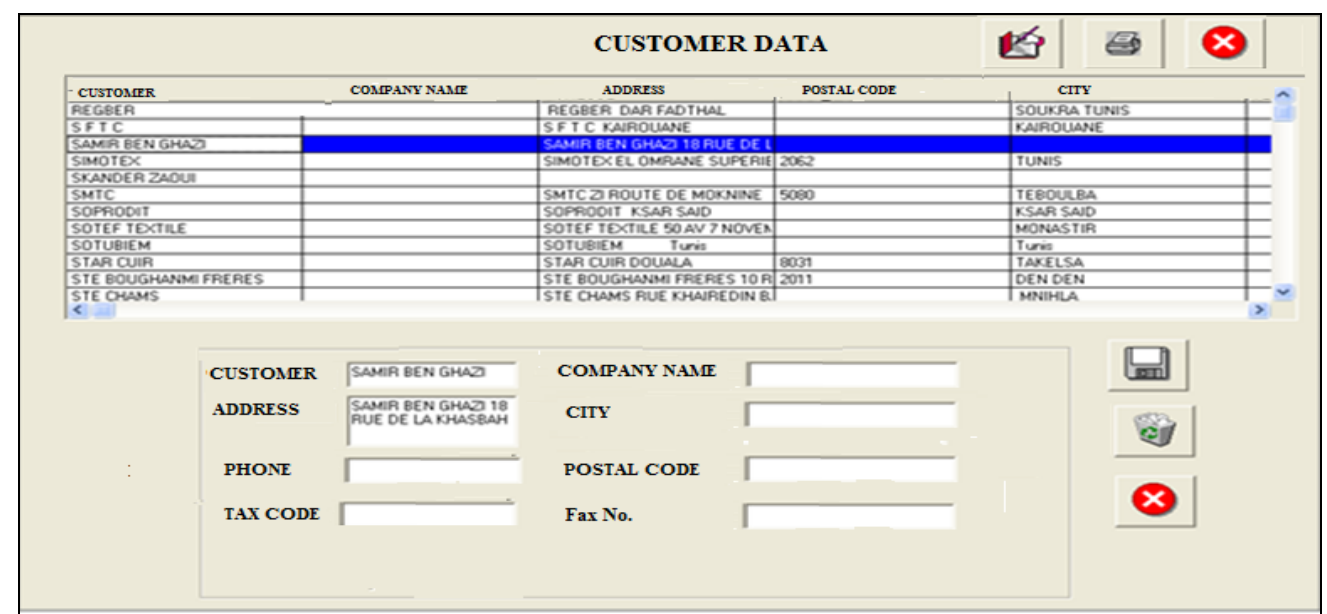

Figure 2: Customer tariff interface.

\section{Colors and products}

The figure 3 allows the entry recording dyes and while indicating the reference product family, description, supplier and the purchase price. This information is needed to determine the cost of production and to control product.

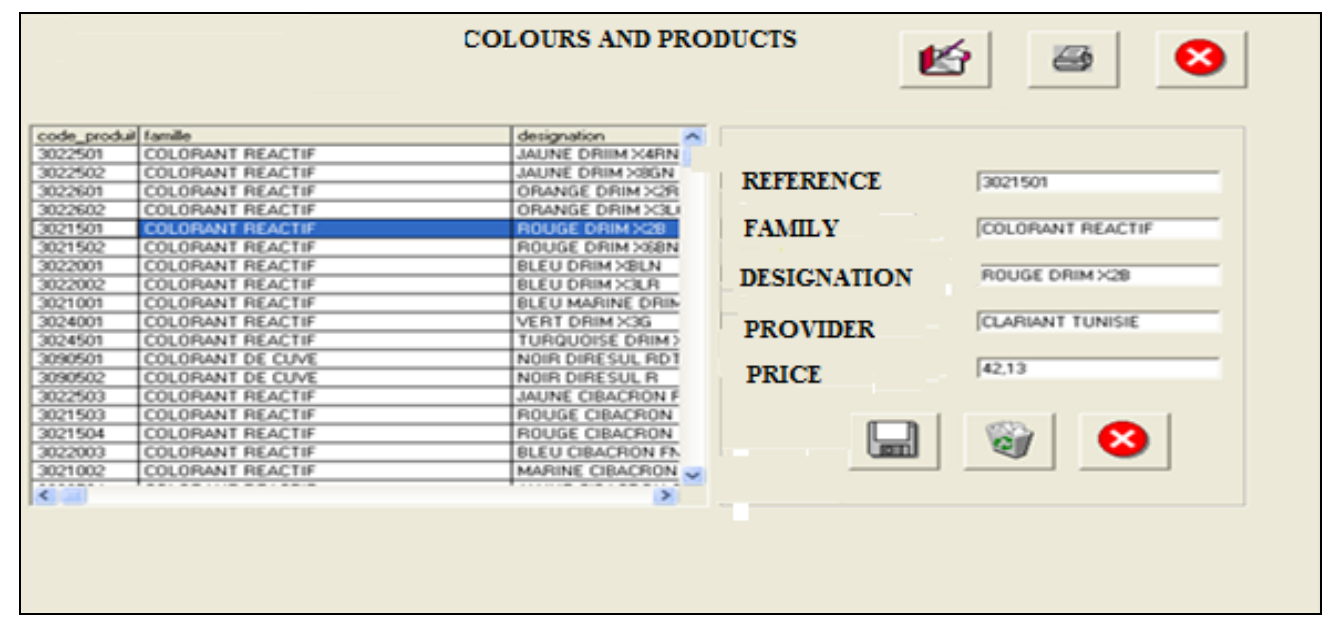

Figure 3: Colors and products Interface.

\section{Machines}

This is the representation of the business or assets of the data we find all the machines( fig.4). Permit for each machine maintenance (maintenance date, type of spare part ...).

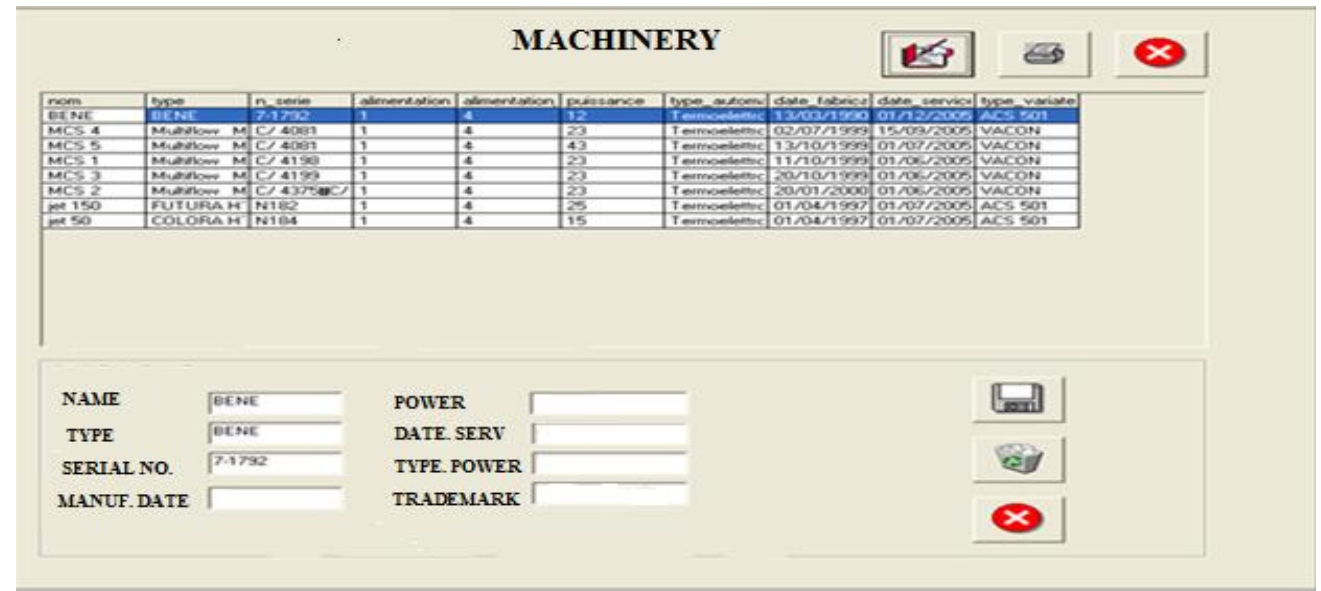

Figure 4: Machines Interface. 


\section{Delivery}

An array of production monitoring displays, upon activation of the interface, indicating the treated groups with the remarks of the visit. The selection of a lot of introduced directly into the base delivery by assigning a delivery. lots are not prepared and delivered remains in storage until the customer's request. This interface (Figure.5) allows the display of all deliveries and filter according to the following criteria: Customer Treatment The delivery date Support.

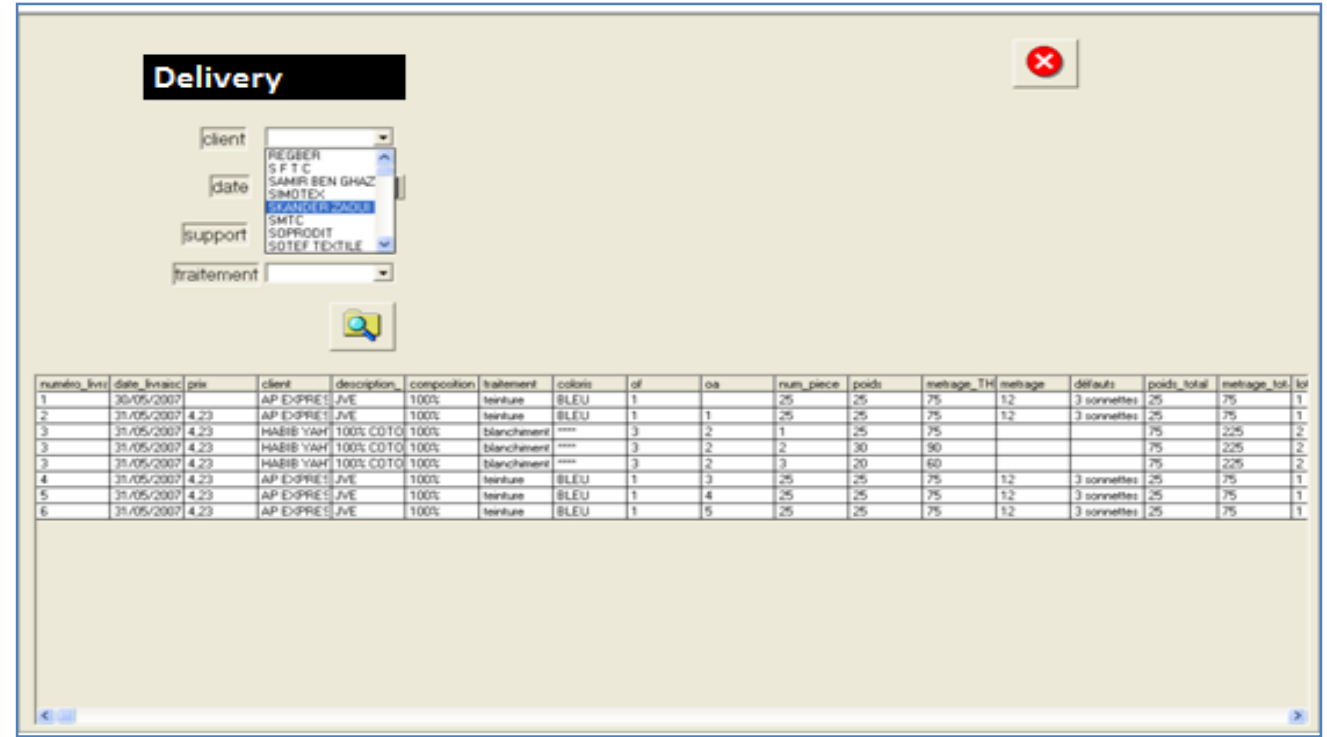

Figure 5: Delivery Interface.

\section{Record process}

The standard modules are standard recipes that make the treatment of dyeing, products used in the recipe (name, percentage by weight of the material, the amount in the bath). The units launched for dyeing are displayed in a table, in figure 6, it can be assigned to each batch the process of matching stain. Once the selected batch number on entry process by a dropdown list (the process from recording standard modules) and the program dyeing and shade. After these two steps a launch window appears and dyeing can starts.

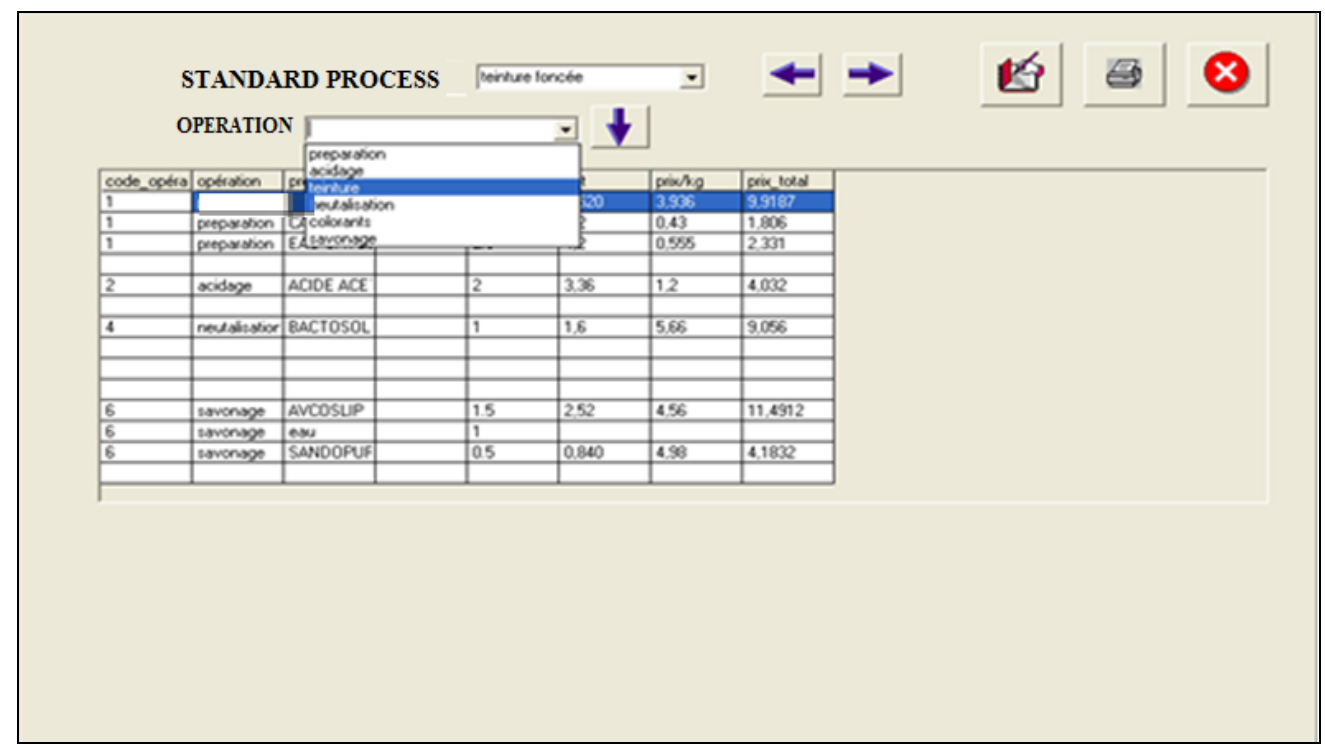

Figure 6: Standard process Interface.

Datasheet colorant store

After the launch of a sheet stock dyeing is prepared and sent to the store of chemicals (figure 7). 


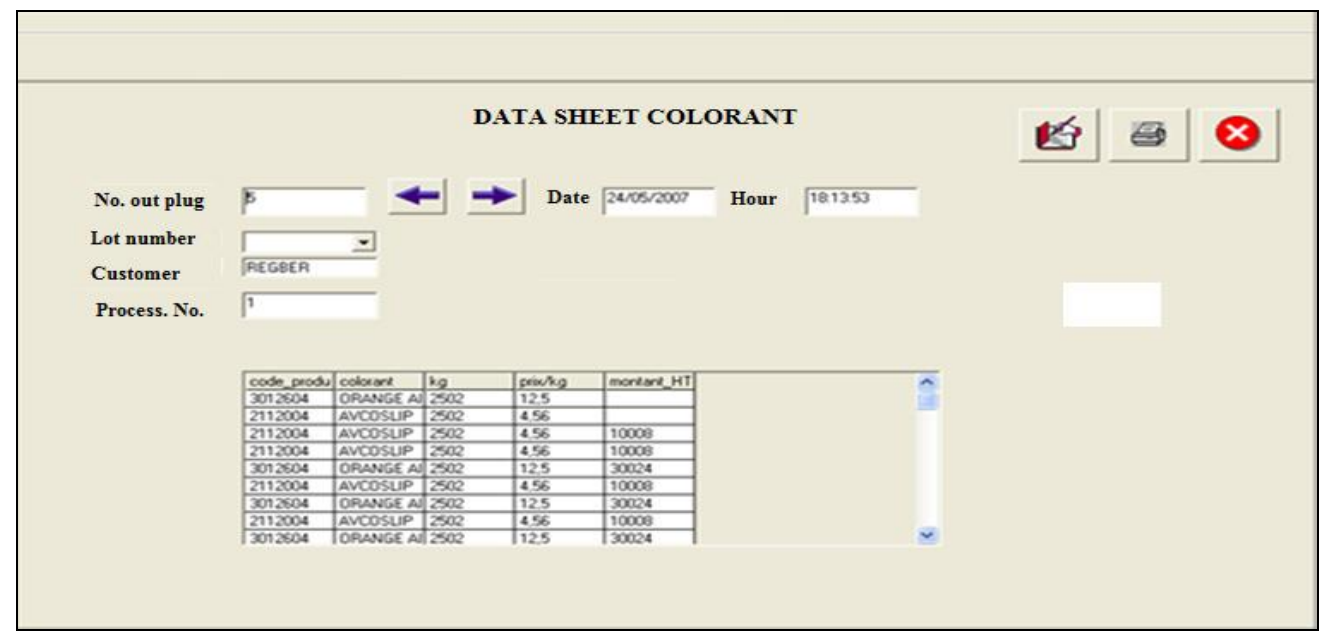

\section{Production monitoring}

Figure7: Record store colorant Interface.

This interface allows the monitoring of the progress of one or more lots in the production. At this level you can specify the remarks quality and production problems (failure, workers ...)

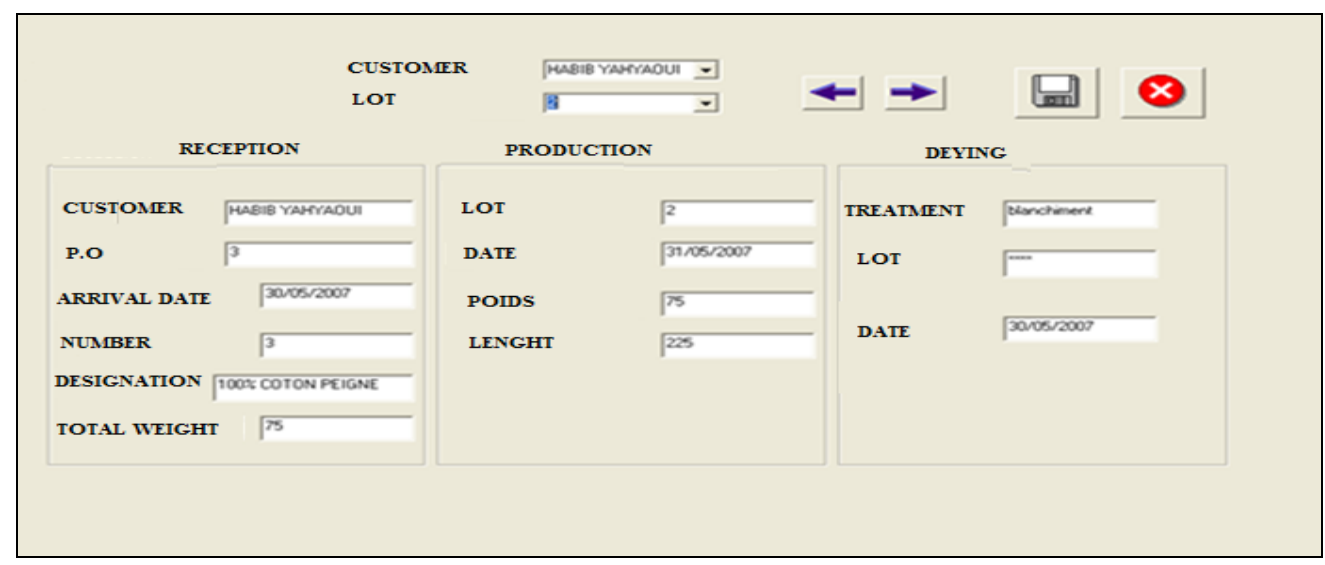

Figure 8: Monitoring Production Interface.

This interface allows the display of all items involved in the production and allows filtering according to the customer, launch date, the media type and nature of treatment.

\section{Establishment control sheet}

The terms of reference given by the client to achieve the required quality is entered in the interface. This interface allows to choose which tests to perform and enter the corresponding results. These results are printed and sent towards the customer.

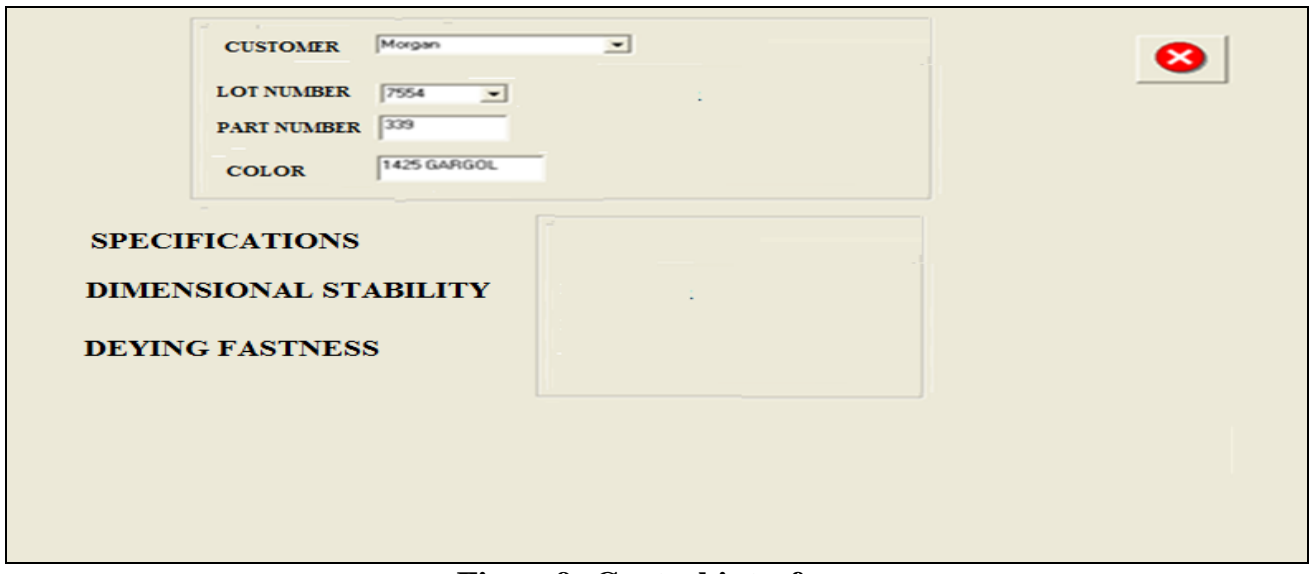

Figure9: Control interface. 


\section{Viewing invoice}

Delivered batches are displayed in this interface to prepare their bills. The price calculation is performed according to the customer to pay and its parameters such as price per kg, VAT customer delivery. This interface shows all invoices prepared and can print.

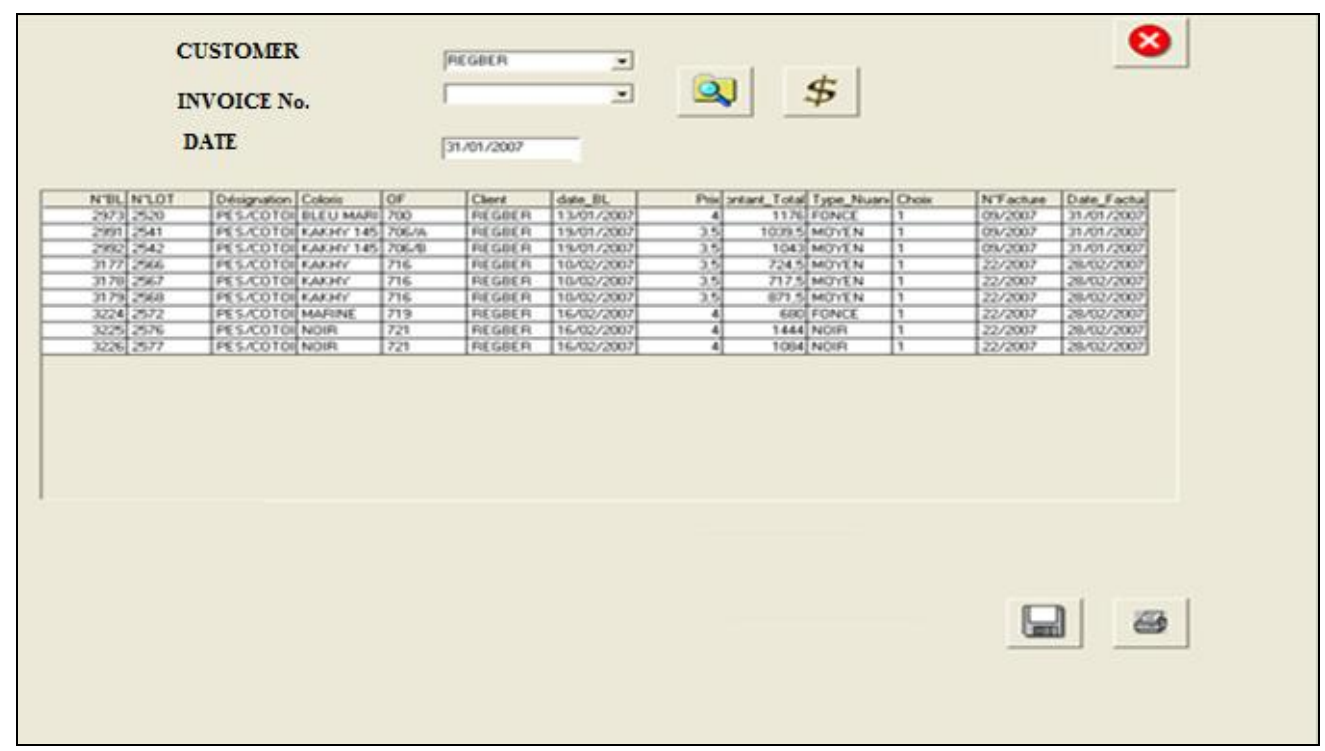

Figure 10: Interface bills.

\section{CONCLUSION}

The future of logistics will be strongly linked to that of the information technology that supports the need for a high processing capacity, flexibility of information systems, computer network architecture most reliable, as well as a platform to help as sturdy as vigorous decision. The mating of Visual Basic and Microsoft Access has allowed the implementation of software that can handle different data and process to provide the user with all information concerning the documentation of business and production management. The software allows for accurate monitoring of production by printing all the different forms required for the production workshops.

\section{REFERENCE}

[1] Casino G., , « NTIC : What do we talk? », study TICO : Information Technology and Communication in Organizations, National Agency for the improvement of working conditions, September. (1999)

[2] François Blondel, Production Management: Understanding the logic of industrial management to act (DUNOD, Factory New, 1999).

[3] Yves. Schoefs, Industrial organization Guide (Editions Delagrave, 2001).

[4] François Blondel, Memory using industrial management (DUNOD Editor, 1999).

[5] Maurice Pillet, Chantal Martin-Bonnefous, Pascal Bonnefous, Alain Courtois, Production management: Fundamental and best practices (Eyrolles, References2011).

[6] WOOD, Ghislaine. Surreal Things, Surrealism and design (Londres: V\&A Publications, Victoria and Albert Museum, 2007). 